\title{
USO EDUCACIONAL DE TABLETS: ESTUDO DE CASO NA FORMAÇÃO INICIAL DE PROFESSORES DE MATEMÁTICA
}

\author{
Gilmara Teixeira Barcelos, IF Fluminense Campus Campos-Centro \\ gilmarab@iff.edu.br \\ Silvia Cristina Freitas Batista, IF Fluminense Campus Campos-Centro \\ silviac@iff.edu.br \\ Larissa da Silva Moreira, IF Fluminense Campus-Itaperuna \\ larissasm@iff.edu.br \\ Patricia Alejandra Behar, NUTED-PGIE/UFRGS \\ patricia.behar@ufrgs.br
}

\section{RESUMO}

As licenciaturas são espaços privilegiados para a discussão sobre o uso de tecnologias digitais na educação. Nesse contexto, o presente estudo tem por objetivo analisar a visão de professores de Matemática em formação sobre a elaboração de mapas mentais em tablets, discutindo vantagens e desvantagens em relação à utilização do computador para o mesmo fim. Para tanto, neste artigo, inicialmente, é abordado o uso pedagógico de tablets e é destacado o papel dos mapas mentais na educação. A seguir, são descritos os procedimentos metodológicos adotados em um estudo de caso promovido na Licenciatura em Matemática de uma instituição federal. Finalizando, são discutidos os dados levantados. Foi verificado que, em geral, a construção dos mapas mentais no computador foi considerada mais fácil do que nos tablets.

Palavras-chave: tablets, mapas mentais, formação de professores, matemática, software Mindomo

\section{EDUCATIONAL USE OF TABLETS: A CASE STUDY IN A CLASS OF UNDEGRADUATE STUDENTS OF MATHEMATICS EDUCATION}

\begin{abstract}
Teacher training courses are privileged spaces to discuss the use of digital technologies in education. This paper aims at analyzing the opinion of future teachers of Mathematics on the construction of mental maps in tablets, its benefits and drawbacks in relation to using traditional computers for the same purpose. Thus, this article begins by discussing the pedagogical use of tablets, and the relevance of using mind maps in education. Following, the paper describes the methodological procedures used in this study carried out at a federal institution. The article closes with a discussion of data obtained in the survey, among them the identification of positive aspects and difficulties found in the use of tablets.
\end{abstract}

Keywords: tablets, mind maps, teacher training, Mathematics, Mindomo software

\section{Introdução}

Os tablets são dispositivos que oferecem diversos recursos que podem facilitar a visualização de conteúdos, estimular atividades cooperativas e o desenvolvimento de projetos e, assim, contribuir para a realização de diversas atividades pedagógicas (Seabra, 2012). No entanto, apesar de todas essas possibilidades, o uso pedagógico dos 
tablets irá requerer um professor preparado, dinâmico e investigativo. Sem um uso adequado, esses dispositivos, assim como qualquer outro recurso, podem ser apenas modismos adestradores de um mercado consumidor (Seabra, 2012).

Diante desse contexto, foi realizado um estudo de caso no qual foi utilizado o software Mindomo ${ }^{1}$, para elaboração de mapas mentais. Um mapa mental, segundo Hermann e Bovo (2005), é basicamente um diagrama hierarquizado de informações, no qual é possível facilmente identificar as relações e os vínculos entre as mesmas. O uso pedagógico desses mapas tem sido analisado por vários pesquisadores (Marques, 2008; Seyihoglu e Kartal, 2010; Keles, 2012), mas, novas formas de uso dos mesmos têm surgido e, portanto, investigações relativas ao assunto são importantes.

O estudo de caso ocorreu em uma disciplina ministrada na Licenciatura em Matemática de uma instituição federal, em fevereiro/março de 2013, com duração de 5 horas. Os professores em formação elaboraram mapas mentais sobre o tema pirâmides, utilizando a versão gratuita do Mindomo para tablets Android e a versão on-line desse software, também gratuita, em computadores.

Assim, este artigo tem por objetivo analisar a visão de professores de Matemática em formação sobre a elaboração de mapas mentais em tablets, discutindo vantagens e desvantagens em relação à utilização da versão on-line em computadores. Para tanto, na seção 2, é abordado o uso pedagógico de tablets. Na seção 3, focaliza-se o papel dos mapas mentais na educação. Na seção 4, são descritos os procedimentos metodológicos adotados no estudo de caso e, na seção 5, são discutidos os resultados encontrados. Finalizando, na seção 6, são apresentadas considerações sobre o estudo promovido.

\section{Uso Pedagógico de Tablets}

Mobile Learning (m-learning) é o campo de pesquisa que estuda como as tecnologias móveis podem contribuir para a educação. Entre os dispositivos para m-learning encontram-se os smartphones e tablets.

Em relação aos tablets, Seabra (2012) afirma que, além do acesso a materiais de pesquisa, esses dispositivos permitem que o aluno interaja com infográficos, simulações e jogos educacionais, realize simulados de provas e exercícios e acesse cursos a distância, entre outras ações. Além disso, os tablets funcionam, também, como máquinas fotográficas, permitindo tirar fotos, editá-las e publicá-las em álbuns on-line ou blogs. Também possuem recursos para gravação de vídeos e arquivos em áudio e são dotados de sensor de posicionamento e GPS, funções que podem ser importantes para trabalhos escolares (Seabra, 2012).

Para Moran (2012), a tela sensível ao toque permite uma navegação muito mais intuitiva e fácil do que com o mouse, mesmo para crianças pequenas. Segundo o autor, com a tendência de barateamento dos dispositivos móveis, os mesmos estarão muito mais presentes dentro e fora da sala de aula, permitindo experimentar muitas formas de pesquisa e desenvolvimento de projetos, jogos, atividades individuais ou em grupo. $\mathrm{O}$ professor não se concentrará tanto em transmitir informações, mas sim em disponibilizá-las e em organizar e gerenciar atividades didáticas significativas desenvolvidas pelos alunos. Os próximos passos na educação estarão cada vez mais interligados à mobilidade, flexibilidade e facilidade de uso que os tablets e outros dispositivos móveis oferecem (Moran, 2012). O autor destaca, ainda, que as tecnologias móveis desafiam as instituições a sair do ensino tradicional em que os professores são o centro, para uma aprendizagem mais participativa e integrada, com momentos presenciais e a distância. No entanto, é preciso considerar que há usos dispersivos e que a concentração em um assunto ou texto pode ser prejudicada pela quantidade de possibilidades oferecidas pelas tecnologias móveis. Tecnologias podem ajudar ou não, 
tudo dependerá de como as mesmas serão integradas à proposta pedagógica (Moran, 2012).

Em um estudo sobre o uso de tablets na educação, Marés (2012) destaca que, embora existam diversos aplicativos educacionais para esses dispositivos, muitos foram concebidos para contextos que não exigem a intervenção de professores. Portanto, a utilização dos mesmos, em sala de aula, pode requerer estratégias adequadas para que esses aplicativos possam colaborar com os objetivos pedagógicos pretendidos. Dados preliminares, segundo Marés (2012), mostram resultados positivos sobre utilização de tablets em níveis iniciais de ensino e na educação de crianças com necessidades especiais. Também há indicativos de que a portabilidade e a conectividade oferecida por esses dispositivos incentivam a colaboração e interação entre alunos em sala de aula. No entanto, tudo isso ainda precisa ser analisado mais profundamente, de forma a determinar as potencialidades e eventuais limitações do uso desses dispositivos na educação (Marés, 2012).

Marés (2012) aponta, ainda, aspectos a serem considerados em um projeto pedagógico envolvendo o uso de tablets: i) conectividade contínua - dada a menor capacidade de armazenamento, os mesmos requerem conectividade contínua, o que no caso dos PC era desejável, mas nem sempre indispensável; ii) consumo x criação de material - no estágio atual, o uso dos tablets é mais simples em termos de consumo de material do que para a criação dos mesmos; iii) desenvolvimento de recursos - trata-se de uma questão complexa, pois exige trabalho multidisciplinar e reflexões sobre práticas pedagógicas; iv) desenvolvimento de protocolos de segurança e proteção contra roubos.

Mang e Wardley (2012) apresentam recomendações para o uso de tablets, a partir de uma experiência promovida com alunos do Ensino Superior, usando iPads. Segundo os autores, é fundamental que os alunos utilizem os dispositivos regularmente nas atividades didáticas, de forma que o uso se torne natural. Nesse sentido, sugerem 0 registro de notas de aula e a realização de pesquisa. Além disso, os autores recomendam que os professores: i) conheçam bem o tablet, antes de utilizá-lo em sala de aula; ii) planejem as atividades; iii) certifiquem-se de poder contar com a colaboração do departamento de Tecnologia da Informação da instituição; iv) descrevam as características e benefícios do uso do equipamento logo no início das atividades; v) reflitam sobre a estratégia de distribuição dos tablets, quando os mesmos forem institucionais.

Como, no estudo de caso descrito, o uso dos tablets envolveu um aplicativo para mapas mentais, discute-se, na seção seguinte, a utilização desses recursos na educação.

\section{Mapas Mentais na Educação}

Um mapa mental é uma ferramenta de organização de ideias por meio de palavraschave, cores e imagens, em uma estrutura que se irradia a partir de um centro (Triboli, 2004). Segundo o autor, a elaboração desses mapas favorece o aprendizado e, consequentemente, melhora a produtividade pessoal. A figura 1 apresenta um exemplo de mapa mental.

Em geral, os mapas mentais são diagramas de uso pessoal, uma vez que contêm símbolos e informações organizadas na ordem e hierarquia que o usuário estabelecer. No entanto, os mesmos também podem ser elaborados coletivamente, desde que os símbolos, códigos e palavras-chave sejam de conhecimento de todos (Hermann; Bovo, 2005). 


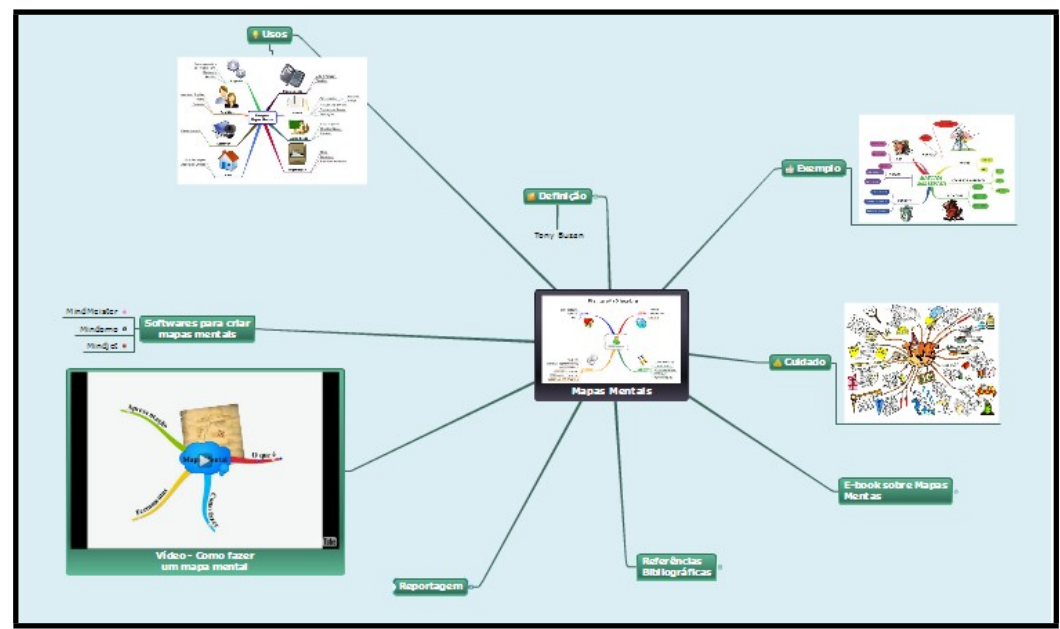

Figura 1- Exemplo de mapa mental

A pesquisa e a organização do conjunto de estratégias relacionadas aos mapas mentais foram empreendidas por Tony Buzan, um dos mais conhecidos pesquisadores do assunto (Hermann e Bovo, 2005; Triboli, 2004). Outro tipo de mapa também bastante utilizado é o mapa conceitual que, segundo Hermann e Bovo (2005), difere do mapa mental, pois as relações podem ser expressas por linguagem, de acordo com a necessidade, e podem conter mais de um centro.

O mapeamento mental pode ser utilizado em quase todas as atividades nas quais o pensamento, a memória, o planejamento e a criatividade estejam envolvidos. No entanto, é preciso ter cuidado para que ideias, relações e hierarquias estejam bem definidas (Hermann; Bovo, 2005). Nesse sentido, algumas vezes é preciso reelaborá-los, até alcançar a estruturação ideal. Essa é uma das maiores vantagens do uso de softwares para elaboração de mapas, já que é possível alterá-los quantas vezes for preciso (Hermann; Bovo, 2005).

Em termos de educação formal, Vilela (2002) lista algumas aplicações dos mapas mentais para o professor: i) planejamento da disciplina; ii) organização do conteúdo a ser abordado; iii) apresentação de conteúdos; iv) elaboração de materiais didáticos; v) registro de estratégias relacionadas ao tema; vi) registro de ideias individuais ou coletivas (por um grupo de professores de uma mesma área, por exemplo); vii) apoio a projetos interdisciplinares. Assim como descreve aplicações para alunos: i) estudo e revisão; ii) elaboração de trabalhos e projetos; iii) memorização; iv) registro de notas de aula; v) apoio à motivação e à aquisição de hábitos de estudos - mapas mentais motivacionais e com estratégias de estudo, por exemplo, podem ser distribuídos aos alunos (Vilela, 2002).

A utilização de mapas mentais na educação tem sido analisada em diversos estudos (Marques, 2008; Seyihoglu e Kartal, 2010; Keles, 2012). De maneira geral, tais estudos apontam contribuições dos mapas mentais para: i) organização de ideias de forma sistemática; ii) estímulo visual; iii) entendimento dos objetivos das atividades; iv) autonomia e criatividade dos alunos; v) processo de memorização. Como desvantagem da técnica do mapeamento mental, foi destacado o tempo necessário para sua utilização. Seyihoglu e Kartal (2010), no entanto, ressaltam que esse problema é minimizado nas aplicações seguintes, uma vez que os alunos vão adquirindo experiência e diminuindo o tempo gasto na utilização da técnica.

Na seção seguinte, são descritos os procedimentos metodológicos adotados no estudo de caso realizado. 


\section{Procedimentos Metodológicos}

Para atingir o objetivo geral da pesquisa, optou-se por realizar um estudo de caso. $\mathrm{O}$ mesmo foi promovido na turma do quarto período da Licenciatura em Matemática de uma instituição federal, na disciplina Geometria IV, ministrada por uma das autoras deste artigo. A turma em questão possuía 11 alunos, mas somente dez participaram do estudo de caso, estando presentes em todos os encontros, que ocorreram em horário regular da disciplina.

Para a elaboração dos mapas mentais, foi selecionado o software Mindomo, que possui uma versão on-line gratuita ${ }^{2}$, em português, e, também, versões gratuitas para iPad e dispositivos com sistema Android. Cabe ressaltar que as versões on-line e para tablets não possuem os mesmos recursos. Há ainda, uma versão desktop, para ser usada off-line no computador.

Os tablets utilizados na pesquisa realizada pertencem ao Projeto Pró-Docência ${ }^{3}$, vinculado à instituição de ensino em questão, e foram adquiridos com verba da CAPES. São sete tablets Motorola XOOM, com sistema operacional Android. Os mesmos são utilizados em ações destinadas a professores em formação, tendo em vista o levantamento de potencialidades e dificuldades do uso pedagógico dos mesmos.

Para o estudo de caso, foram organizados três encontros. O primeiro, com duração de 1 h 30 min, teve em vista as seguintes ações: i) solicitar o cadastramento dos alunos no site do Mindomo, na versão on-line; ii) discutir a definição e aspectos relacionados aos mapas mentais, por meio de uma apresentação elaborada no Mindomo e, colocada em modo de apresentação de slides, por meio de recurso do próprio software; iii) experimentar os recursos do Mindomo, no computador; iv) solicitar o planejamento de um mapa sobre o tema pirâmides, a ser desenvolvido no segundo encontro.

O tema para a elaboração dos mapas mentais foi pirâmides pelo fato desse ser o assunto cujo estudo estava sendo finalizado, no período da pesquisa, na disciplina Geometria IV. Assim, a proposta da elaboração dos mapas mentais tinha a finalidade de analisar os conhecimentos dos sujeitos da pesquisa e verificar como os mesmos utilizariam os recursos do software (no tablet e no computador) para planejar uma aula sobre o tema.

O segundo encontro, com duração de $1 \mathrm{~h} 30 \mathrm{~min}$, teve como objetivo elaborar os mapas mentais, utilizando a versão do Mindomo para tablets Android e a on-line, no computador. O terceiro encontro durou 2 horas e foi destinado à apresentação e discussão dos mapas elaborados pelos alunos e à proposta de um questionário sobre a visão dos mesmos a respeito dos recursos utilizados e sobre a experiência de uso.

Para a coleta de dados, foram adotados os seguintes instrumentos: observação, questionário e conteúdo dos mapas construídos pelos professores em formação. Os dados foram analisados segundo uma abordagem, predominantemente, qualitativa.

Na seção seguinte, são discutidos os resultados obtidos na experiência promovida.

\section{Análise e Discussão dos resultados}

No primeiro encontro, foram promovidas as atividades mencionadas na seção 4. Os alunos manifestaram muito interesse no Mindomo e testaram os recursos com facilidade, utilizando a versão on-line no computador.

No segundo encontro, foram formadas quatro duplas e duas pessoas optaram por trabalhar sozinhas. Cada dupla recebeu um tablet, assim como cada estudante que optou por atuar sozinho. Os alunos participaram ativamente da construção dos mapas. Como o Mindomo é de fácil utilização, não ocorreram muitas dúvidas. O maior problema ocorreu em relação à inserção de imagens. No aplicativo do tablet (versão gratuita), não foi possível, no período da pesquisa, buscar pirâmides relacionadas à Matemática. Esse 
fato já havia sido identificado, previamente, pelas pesquisadoras, mas, ainda assim, os alunos foram incentivados a testar a inserção das imagens das pirâmides, para que pudessem observar as possibilidades e restrições de cada versão. A solução proposta foi que os alunos continuassem a elaboração dos mapas nos tablets e, posteriormente, inserissem as imagens na versão on-line, após sincronização das duas versões. Certamente, isso foi um fator limitador do uso do recurso (na versão gratuita para tablet Android), mas é importante que, como futuros professores, os alunos tomem consciência de limitações desse tipo.

Os professores em formação não concluíram seus mapas, ficando a conclusão para ser realizada em horários extras à sala de aula, na versão on-line, no computador.

A apresentação dos mapas foi realizada no terceiro encontro. No total, foram elaborados seis mapas preparados por quatro duplas e duas alunas que fizeram individualmente. Foi possível perceber que os professores em formação estudaram intensamente os temas apresentados, indo além do que havia sido abordado nas aulas.

Embora o conteúdo em estudo fosse o mesmo para todos os alunos, os mapas foram bastante distintos. As figuras 2 e 3 mostram dois dos mapas elaborados e permitem observar isso. As possibilidades de representação que o mapa mental disponibiliza dão liberdade para criar ou adaptar informações. Além disso, os mapas possibilitaram a descoberta de novas relações entre dados, a identificação de novas informações e a reinserção de dados em categorias mais gerais, conforme afirmam Hermann e Bovo (2005).

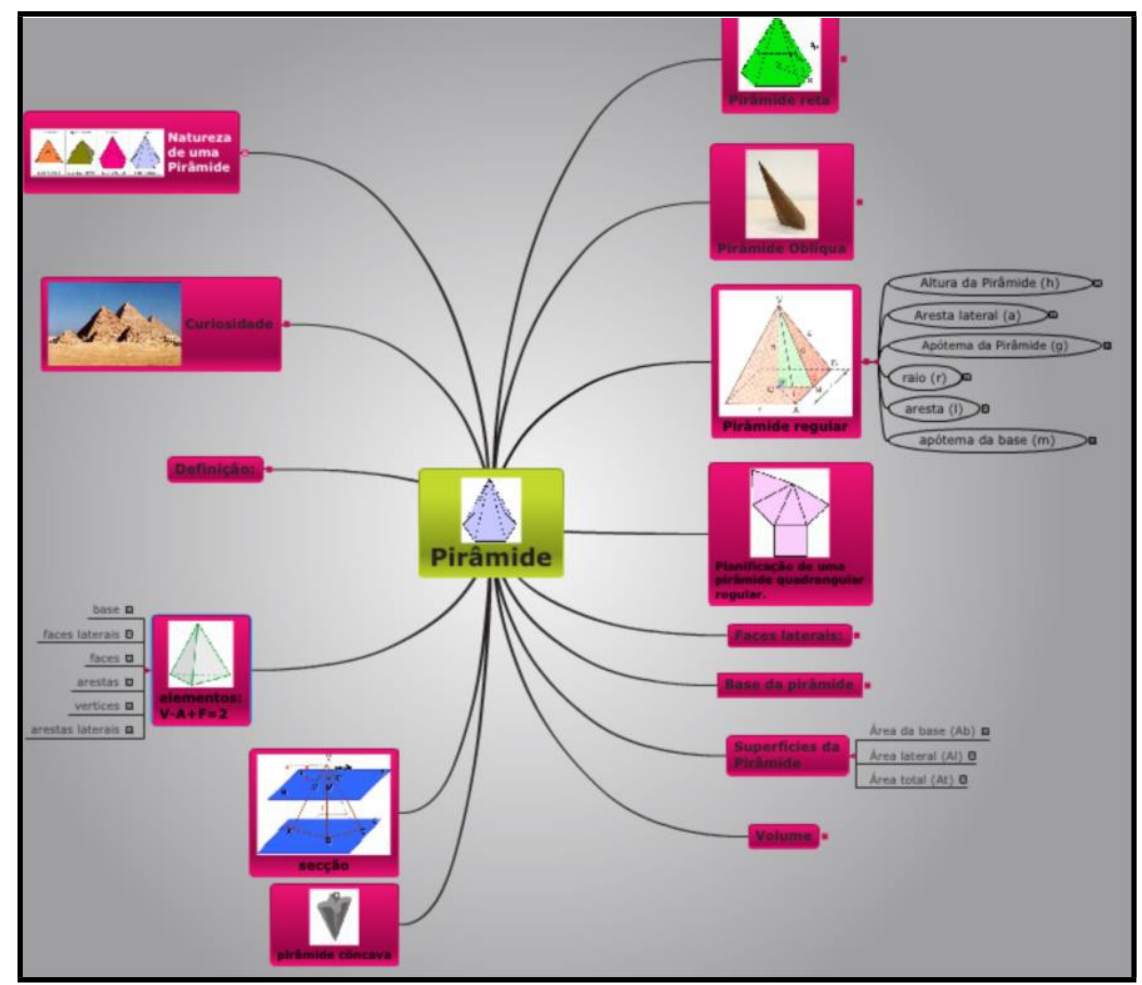

Figura 2 - Mapa 2 


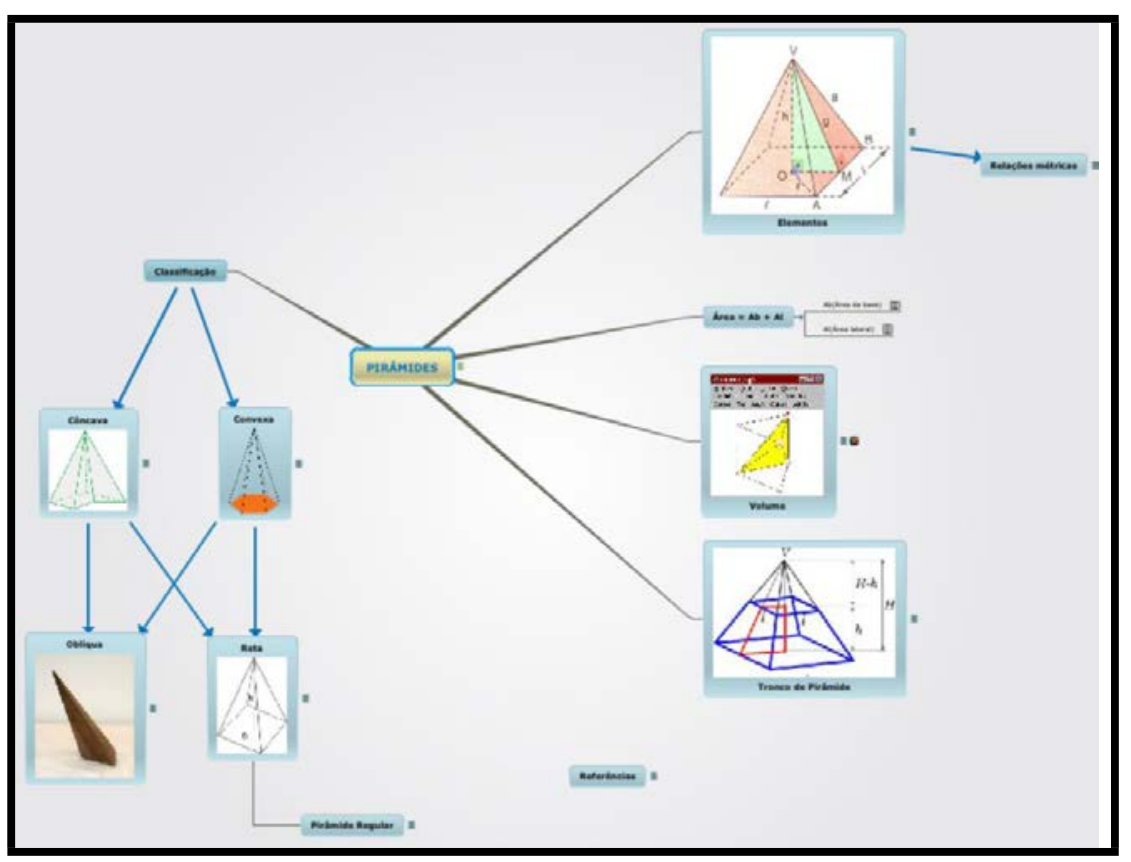

Figura 3: Mapa 3

Ao final do terceiro encontro, todos os sujeitos da pesquisa responderam a um questionário, que visou levantar dados sobre a experiência promovida e sobre os recursos utilizados. Os resultados são discutidos a seguir.

Dos dez professores em formação, 30\% tinha idade entre 19 e 20 e os demais estavam na faixa etária de 21 a 26 anos. Metade dos alunos afirmou já ter utilizado tablet para fins pedagógicos, antes do estudo de caso promovido. Para esses, foram apresentadas as opções mostradas na Tabela 1, solicitando que os mesmos indicassem a finalidade do uso pedagógico dos tablets (era possível assinalar mais de uma opção).

Tabela 1 - Finalidade do Uso Pedagógico de Tablets

\begin{tabular}{l|c}
\hline \multicolumn{1}{c|}{ Finalidade } & Alunos (\%) \\
\hline Estudar para prova & 0 \\
\hline Realizar pesquisa & 20 \\
\hline Preparar aula no contexto de alguma disciplina & 40 \\
\hline Realizar uma atividade ou trabalho acadêmico & 100 \\
\hline Utilizar um aplicativo educacional & 0 \\
\hline Fotografar ou realizar filmagens com fins educacionais & 0 \\
\hline Gravar entrevistas para alguma atividade pedagógica & 0 \\
\hline Participar de chats ou fóruns sobre temas educacionais & 0 \\
\hline Outra finalidade & 40 \\
\hline
\end{tabular}

Observa-se que, dos cinco professores em formação que responderam afirmativamente, nenhum utilizou aplicativos educacionais ou mesmo usou recursos de filmagem e fotografia para fins pedagógicos. Como esses são recursos bastante comuns entre os jovens, havia a expectativa de que os mesmos receberiam um percentual maior. Com relação à opção “Outras finalidades”, a mesma foi assinalada por dois alunos que apresentaram a mesma justificativa: ambos já utilizaram tablet para responder a uma prova feita virtualmente.

Quanto à utilização do Mindomo, para construção de mapas mentais, foram propostas cinco afirmativas diante das quais os dez alunos deveriam assinalar uma das opções: Concordo Completamente (CC), Concordo (C), Não Concordo Nem Discordo 
(NC ND), Discordo (D) e Discordo Completamente (DC). A Tabela 2 mostra os resultados obtidos.

Tabela 2 - Utilização do Mindomo

\begin{tabular}{l|c|c|c|c|c}
\hline \multicolumn{1}{c|}{ Opções } & $\begin{array}{c}\text { CC } \\
\text { \% }\end{array}$ & $\begin{array}{c}\text { C } \\
\mathbf{\%}\end{array}$ & $\begin{array}{c}\text { NC ND } \\
\mathbf{\%}\end{array}$ & $\begin{array}{c}\mathbf{D} \\
\mathbf{\%}\end{array}$ & $\begin{array}{c}\text { DC } \\
\text { Afirmativas }\end{array}$ \\
\hline $\begin{array}{l}\text { Utilizar os recursos do Mindomo no } \\
\text { tablet foi fácil. }\end{array}$ & 20 & 50 & 10 & 10 & 10 \\
\hline $\begin{array}{l}\text { Utilizar os recursos do Mindomo no } \\
\text { computador foi fácil. }\end{array}$ & 50 & 40 & 0 & 0 & 10 \\
\hline $\begin{array}{l}\text { As ferramentas do Mindomo, no tablet, } \\
\text { são satisfatórias. }\end{array}$ & 0 & 30 & 40 & 30 & 0 \\
\hline $\begin{array}{l}\text { As ferramentas do Mindomo, no } \\
\text { computador, são satisfatórias. }\end{array}$ & 40 & 40 & 0 & 10 & 10 \\
\hline $\begin{array}{l}\text { A utilização do Mindomo contribuiu } \\
\text { para a preparação do trabalho solicitado. }\end{array}$ & 60 & 30 & 0 & 0 & 10 \\
\hline $\begin{array}{l}\text { A possibilidade de utilizar o Mindomo } \\
\text { de forma colaborativa foi importante } \\
\text { para o desenvolvimento do trabalho }\end{array}$ & 50 & 30 & 10 & 0 & 10 \\
\hline
\end{tabular}

Os dados da Tabela 2 permitem observar que a facilidade de utilização dos recursos do Mindomo foi melhor avaliada no computador. Atribui-se esse resultado à maior familiaridade com programas de computador e à possibilidade de uso de alguns atalhos do teclado e à utilização do mouse. É importante considerar, ainda, que como os tablets não eram dos alunos não houve possibilidade de investigação dos recursos fora do tempo da aula, como fizeram no computador. Nesse sentido, Mang e Wardley (2012) defendem que é essencial que os alunos utilizem os dispositivos regularmente nas atividades didáticas para que uso educacional dos tablets se torne natural. Uma pergunta aberta solicitando pontos negativos e positivos das duas versões do Mindomo permitiu levantar opiniões dos alunos que justificam a visão mais favorável ao computador, como as duas apresentadas abaixo:

Facilidade para digitação, facilidade para utilizar recursos como mover e marcar utilizando o mouse no computador/notebook (Aluno C);

O Mindomo no computador é melhor pra montar o mapa pelo fato de ter um monitor, mouse e teclado (Aluno $\mathrm{H}$ ).

Em relação às ferramentas serem satisfatórias, a melhor avaliação também foi para versão do computador. Como mencionado anteriormente, a busca por pirâmides no contexto da Geometria não foi possível na versão gratuita para tablet Android, na época da pesquisa. Isso justifica a melhor avaliação das ferramentas na versão do computador. Os comentários dos alunos, apresentados abaixo, ratificam essa visão.

É complicado pra digitar, pelo teclado ser digital. A ferramenta de imagem não foi possível utilizar (Aluno G);

Um ponto negativo no tablet é não poder colocar imagens, quando se colocava para pesquisar imagens não vinha nenhuma opção (Aluno J).

Quanto à utilização do Mindomo ter contribuído para a preparação do trabalho solicitado, os resultados obtidos foram positivos, o que sinaliza que o software, de modo geral, foi bem aceito pelos alunos. As opiniões dos alunos, apresentadas abaixo, levantados por meio de outra questão aberta que solicitava comentários gerais sobre Mindomo ou sobre a participação dos mesmos nas atividades desenvolvidas, também sinalizam nesse sentido. 
O mindomo é muito interessante, ele pode contribuir muito para a elaboração de muitos trabalhos, inclusive para a apresentação de aulas (Aluno E);

Eu gostei muito de utilizar o mindomo, pois a apresentação ficou muito mais dinâmica. E a apresentação como um resumo, contribuiu pra melhor o estudo. Pois foi preciso estudar bastante para preparar um mapa mental (Aluno $H$ ).

Da mesma forma, observa-se que a importância da possibilidade de utilizar o Mindomo de forma colaborativa também foi bem avaliada. Como os alunos tiveram que concluir seus mapas em horários extraclasses, os mesmos tiveram possibilidade de trabalhar colaborativamente, mesmo não estando juntos fisicamente. Isso foi feito por meio do computador, mas, é importante ressaltar que toda modificação promovida ficou disponível também no tablet, pela possibilidade de sincronização entre as versões. As opiniões abaixo destacam essa possibilidade como pontos positivos do Mindomo.

Compartilhar o mapa com o colega do grupo, o melhor que ambos podem fazer alterações (Aluno F);

Compartilhar o mapa com outras pessoas, ela poderá modificá-lo ou só visualizá-lo (Aluno I).

Em resumo, os pontos positivos ${ }^{4}$ levantados pelos alunos sobre o Mindomo para Android em relação à versão on-line, foram a mobilidade do dispositivo, permitindo acesso a qualquer momento, e a possibilidade para salvar, gratuitamente, mais de três ${ }^{5}$ mapas mentais. Já o ponto negativo foi a dificuldade com a inserção de imagens.

Em relação ao uso do tablet em si, a falta de certos recursos habituais, acessíveis via teclado do computador/notebook, foi uma dificuldade mencionada pelos alunos. Essa visão está de acordo com Marés (2012) quando afirma que, no estágio atual, o uso dos tablets é mais simples em termos de consumo de material do que para a criação dos mesmos. Aliás, de maneira geral, entende-se que a visão dos professores em formação está coerente com a literatura da área, mencionada neste artigo.

\section{Considerações finais}

A experiência promovida permitiu observar uma dificuldade em experiências que utilizam tablets institucionais, que apenas ficam com os alunos no período de utilização em sala de aula. Há pouco tempo para os alunos experimentarem os recursos e a falta de familiaridade com o equipamento pode prejudicar, de certa forma, o desenvolvimento das atividades.

Em relação aos alunos considerados no estudo de caso, os mesmos, de maneira geral, não tinham muita intimidade com o uso de tablets. No entanto, isso não ocasionou problemas. Os alunos participaram ativamente da elaboração dos mapas nos tablets, sem demonstrar dificuldades que comprometessem o trabalho. Porém, em geral, os professores em formação consideraram mais fácil a construção de mapas no computador do que nos tablets.

É importante ressaltar a receptividade dos alunos à proposta do uso dos mapas mentais, com os recursos utilizados. A mesma foi excelente, superando até mesmo a expectativa das pesquisadoras. A elaboração dos mapas permitiu uma reflexão mais profunda sobre o tema abordado. Os alunos, embora já tendo estudado o tema pirâmides para a realização de uma prova, tiveram que rever todo o conteúdo, identificando relações que não haviam ficado claras antes.

De forma geral, quanto aos dispositivos móveis, entende-se que gerações futuras, ainda mais familiarizadas com os mesmos, poderão tirar proveito desses recursos, em termos educacionais, com facilidade, se forem bem orientadas nesse sentido. 


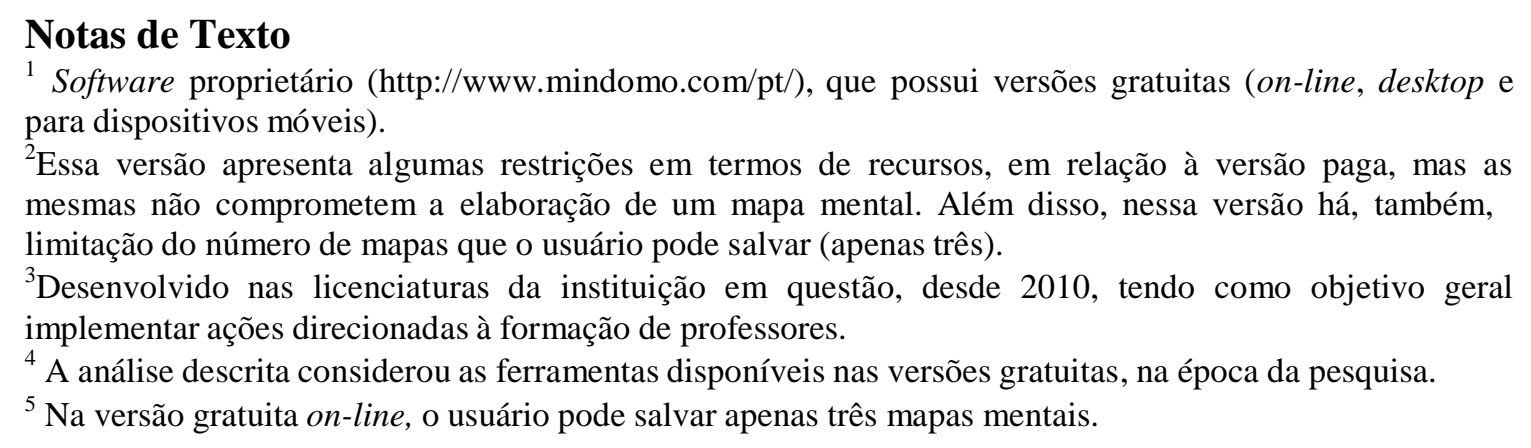

\section{Referências Bibliográficas}

HERMANN, W; BOVO, V. Mapas Mentais: Enriquecendo Inteligências. 2. ed. Campinas: Instituto do Desenvolvimento do Potencial Humano (IDPH), 2005.

KELES, O. Elementary Teachers' Views on Mind Mapping. International Journal of Education, Las Vegas, EUA. v.4, n.1, p.93-100, 2012. Disponível em: $<$ http://www.macrothink.org/journal/index.php/ije/article/view/1327/1211> Acesso em: 18 fev. 2013.

MANG, C. F.; WARDLEY, L. J. Effective Adoption of Tablets in Post-Secondary Education: Recommendations Based on a Trial of iPads in University Classes. Journal of Information Technology Education: Innovations in Practice, EUA. v.11, p. 301317, 2012. Disponível em: <www.jite.org/documents/Vol11/JITEv11IIPp301317Mang1138.pdf > Acesso em: 12 fev. 2013.

MARÉS, L. Tablets in Education: opportunities and challenges in one-to-one programs. 2012. Estudo realizado pela Rede Latinoamericana de Portais Educativos, com contribuição da Organizacão de Estados Iberoamericanos (OEI), Buenos Aires, Argentina. Disponível em: <http://www.relpe.org/wpcontent/uploads/2012/04/Tabletsin-education.pdf> Acesso em: 12 fev. 2013.

MARQUES, A. M. M. Utilização Pedagógica de Mapas Mentais e de Mapas Conceituais. Portugal, Universidade Aberta, 2008. 153p. Dissertação de Mestrado. Disponível em: <http://hdl.handle.net/10400.2/1259>. Acesso em: 18 fev. 2013.

MORAN, J. M. Tablets e netbooks na educação, 2012. Disponível em: <http://www.eca.usp.br/moran/> Acesso em: 12 fev. 2013.

SEABRA, C. Tablets na sala de aula. 2012. Disponível em: $<$ http://cseabra.wordpress.com/2012/04/22/tablets-na-sala-de-aula/>. Acesso em: 12 fev. 2013.

SEYIHOGLU, A.; KARTAL, A. The Views of the Teachers about the mind mapping technique in the Elementary Life Science and Social Studies lessons Based on the Constructivist Method. Educational Sciences: Theory and Practice, Istambul, Turquia. v.10. n.3, p.1637-1656, 2010. Disponível em: <http://www.edam.com.tr/kuyeb/pdf/en/8a4f04daf7a0c1fc52552051d2f6a75agluEN.pdf >. Acesso em: 12 fev. 2013.

TRIBOLI, E. P. de R. Mapas mentais: uma introdução. Apostila. São Caetano do Sul: Escola de Engenharia Mauá, 2004. Disponível em: $<$ http://www.mapasmentais.com.br/recursos/publicacoes.html> Acesso em: 30 jan. 2013. VILELA, V. V. Mapas mentais na escola: como usar essas ferramentas de pensamento e organização para maior efetividade. Apostila. Brasília, DF, 2002. Disponível em: <http://www.mapasmentais.com.br/recursos/publicacoes.html>. Acesso em: 30 jan. 2013. 